\title{
Assessment of health literacy of municipal employees in Shemiranat, Iran
}

\author{
Mahnaz Solhi ${ }^{1}$, Hanieh Jormand ${ }^{2}$
}

${ }^{1}$ Ph.D. of Health Education and Health Promotion, Associate Professor, Department of Health Services and Health Education, School of Health, Iran University of Medical Sciences, Tehran, Iran

${ }^{2}$ Ph.D. Candidate in Health Education and Health Promotion, Department of Public Health, School of Health, Hamadan University of Medical Sciences, Hamadan, Iran

\section{Type of article: Original}

\begin{abstract}
Background: Health literacy is one of the major determinants of health promotion among individuals and within society.

Objective: The present study is aimed to determine the health literacy status of office employees in Shemiranat using the native instruments of health literacy for Iranian adults (HELIA).

Methods: The present descriptive-analytical cross-sectional study was done in 2016-17. It was conducted on 360 office employees in Shemiranat. The samples were selected using a multi-stage simple random sampling method. Data collection tools in this study included HELIA questionnaire. The data were imported into SPSS v.18 software and then analyzed using descriptive statistical indices (mean, SD, number, and percentage) and inferential statistics (Chi-square, Pearson's correlation coefficient, Spearman's correlation coefficient, and Kruskal-Wallis test). Written informed consent was obtained from the employees participating in the study and they were assured about confidentiality. Also, they were informed that participation was voluntary.

Results: The mean and standard deviation of the total health literacy score among the studied individuals was $125.99 \pm 16.01$. The mean score of health literacy in the areas of reading (15.36 \pm 2.89$)$ and evaluation (5.01 \pm 2.8$)$ among the studied individuals was lower than other dimensions of health literacy. Based on the Chi-square test, there was a statistically significant relationship between health literacy and education level, occupational rank, work place, and work experience ( $\mathrm{p}=0.0001$ in all the cases). The individuals with medium and good levels of health literacy acquired most of their health-related information through the Internet, friends, relatives, physicians, and health staff.

Conclusion: Health literacy status was not sufficient among the studied staff. Thus, it is recommended to perform promotional interventions in order to improve the health literacy status and its dimensions among these staff.
\end{abstract}

Keywords: Health literacy, Employees, Questionnaire

\section{Introduction}

Health literacy is one of the essential concepts in the issue of health (1). According to the WHO's definition, health literacy refers to an individual's socio-cognitive skill for accessing, understanding, and applying health information in order to prevent and promote health (1). Furthermore, health literacy determines the individual's capability and motivation for accessing, understanding, comprehending, and applying the information for a health-promoting behavior (1) predictors of health behaviors and situations as well as other health outcomes $(2,3)$. The findings of Rodford et al. on women with a family history of breast cancer indicated a relationship between low-risk perception and insufficient health literacy (4). Insufficient health literacy can indeed be defined as a silent epidemic affecting the population health care system in many parts of the world, which can result in many unpleasant consequences for

\section{Corresponding author:}

Hanieh Jormand, Department of Public Health, School of Health, Hamadan University of Medical Sciences, Hamadan, Iran. Tel: +98. 81383816428, Fax:+98.8138380509, Email: jormand69h@gmail.com

Received: April 08, 2017, Accepted: July 03, 2017, Published: December 2017

iThenticate screening: June 19, 2017, English editing: August 15, 2017, Quality control: November 21, 2017

This article has been reviewed / commented by five experts

(C) 2017 The Authors. This is an open access article under the terms of the Creative Commons Attribution-NonCommercialNoDerivs License, which permits use and distribution in any medium, provided the original work is properly cited, the use is non-commercial and no modifications or adaptations are made. 
health. In the 5th Conference on Health Promotion in Mexico, the WHO announced that health literacy can be considered not only as a personal characteristic, but also as a key determinant of health promotion at population level (1). Insufficient health literacy would result in considerable costs for hospitalization as well as increased use of treatment services (5). Health literacy refers to any individual's capacity to acquire, interpret, and understand the basic information on health and health services, which is required to make appropriate decisions (6). Regarding various aspects of literacy, each person requires five types of competency: 1) access, which refers to the ability to understand accessible health information, 2) reading health information, which means reading health-training materials, medical forms, guidelines (instruction manuals), pre-test preparation sheets, and specific written instructions provided by the health care staff for different diseases, 3) understanding ability, which refers to the ability to understand health information, 4) evaluating, which means the ability to interpret, filter, judge, and evaluate health information, and 5) applying and decision-making, refers to the ability to establish a relationship and apply the information to make decisions leading to health promotion $(7,8)$. Various instruments have been designed and used throughout the world to measure health literacy (9-13). In Iran, a native instrument has been designed and psychometrically evaluated by Montazeri et al. to measure the health literacy of the urban population (18-65 years old). This instrument is named Health Literacy for Iranian Adults (HELIA) which includes 5 areas (access, reading, understanding, evaluation, and decision-making) and 33 items (14). The low number of questions, ease of implementation, covering all aspects of health literacy (access, reading, understanding, evaluation, decision), and public nature are among the features of this instrument so that it is not for a specific job, education level, or age group, and can be used for different demographic groups. Moreover, this instrument is capable of measuring the health literacy level with acceptable accuracy $(14,15)$. Worldwide, at least one in 10 adults lacks level 1 health literacy. Nearly half of European adults have "inadequate" or "problematic" health literacy, and only $12 \%$ of US adults possess a "proficient" standard (16). In a national study in Iran, about $44 \%$ of the population had limited health literacy (7). In other study, the health literacy level in $79.6 \%$ of the elderly was very poor (1). With respect to the necessity of using this psychometrically evaluated instrument (HELIA) for different groups of adults, the present study is aimed to determine the health literacy status of the office employees in Shemiranat using the native valid and reliable instrument (HELIA). The researchers were native to Shemiranat and office employees in Shemiranat were available groups. These were the reasons for conducting the study. Results of this study can be the use of the Iranian health literacy tool in different groups and it can be used for designing promotional interventions in order to improve the health status and health literacy of these employees.

\section{Material and Methods \\ 2.1. Study design}

This is a descriptive-analytical cross-sectional study which was conducted from October 2016 through March 2017 in Shemiranat, Iran. The population of which included the staff of the Municipal Offices in Shemiranat, Iran. The inclusion criteria included being an employee in one of the offices of Shemiranat County and an education level of above high school diploma. The exclusion criteria included the lack of consent for cooperation and incomplete questionnaires.

\subsection{Subjects and sampling}

The sample size was calculated as equal to 360 individuals, using Cochran's sample size formula with a certain population (4000 people) and considering the confidence level of $95 \%$, initial error of 0.05 , health literacy ratio of 0.5 was obtained by Montazeri et al. on health literacy of Iranian adults living in cities, q=1-0.5, accuracy of 0.05, and possible loss of $10 \%$ (7). Written informed consent was obtained from the employees participating in the study and they were assured about confidentiality. Also, they were informed that participation was voluntary. Sampling was performed using a multi-stage simple random sampling method, among the offices in Shemiranat. There were 15 offices in Shemiranat, 5 offices were randomly selected to provide the estimated number of samples. These offices included Municipality of Area 5 in District 1, Research Center of Municipality, two branches of Shahr Bank, and Municipality of Area 1 in Shemiranat. District 1 has 10 areas which have no discernible differences with each other. Then, in each office, out of the list of employees, a number of employees were selected through simple random sampling. The participants from these offices included 48 individuals from the Municipality of Area 5, 92 individuals from the Research Center of Municipality, 60 individuals from the two branches of Shahr Bank, and 160 individuals from the staff of the Municipality of District 1 in Shemiranat County.

\subsection{Instrument}

Data collection was performed using HELIA, which has been designed and psychometrically evaluated by Montazeri et al. (2014) to measure health literacy of adults in an urban population. This questionnaire includes 7 
questions on demographic characteristics of the respondents and 33 main items in five areas of access (6 items), reading skill (4 items), understanding ( 7 items), evaluation (4 items), decision-making and applying health information (12 items). The scale of responding to the items was a 5-point Likert scale, including always, often, sometimes, rarely, and never $(7,15)$, so that the minimum and maximum points in this questionnaire were 33 and 165, respectively. The questionnaire was used and validated by Montazeri et al. in 2014. The time for completing the questionnaire is $10 \mathrm{~min}$. The scores obtained from this questionnaire were classified using mean $\pm \mathrm{SD}$ criterion so that the score below 110,110-142, and above 140.1 indicated poor, medium, and good health literacy, respectively. The questionnaires were anonymous and the samples were ensured of the confidentiality of their information. The questionnaires were completed by the researchers and two trained questioners in the samples' work places.

\subsection{Statistical Analysis}

Data were imported in SPSS version 18 software and, then, their normality was specified using KolmogorovSmirnov test. Afterwards, data analysis was performed using descriptive statistical indices (mean, SD, number, and percentage) and Inferential statistics (Chi-square, Pearson's correlation coefficient, Spearman's correlation coefficient, and Kruskal-Wallis test).

\section{Results}

The mean and standard deviation of the participants' age was $32.46 \pm 7.03$. Furthermore, $41.1 \%$ and $58.6 \%$ of them were female and male, respectively. Among the participants, 35.6\% had Bachelor's degree, 44.1\% worked in the Municipality of District 1 , and $68.1 \%$ had a work experience of less than 10 years. According to Chi-square test, there was a statistically significant relationship between health literacy and education level, occupational rank, work place, and work experience $(\mathrm{p}=0.0001$ in all the cases) so that the participants with MSc degrees and the occupational ranking of experts had good health literacy. The health literacy status among the samples working in the Research Centre of Municipality and those with a work experience of less than 10 years, was medium and good, respectively (Table 1). Moreover, findings of the present study, in terms of health information sources, showed that the participants acquired most of their information through the Internet. Based on the Chi-square test, there was a significant difference between the health literacy levels acquired through different information sources, including the Internet $(p=0.015)$, friends $(p=0.0001)$, and physicians and health staff $(p=0.0001)$, so that the participants with medium and good health literacy obtained the health-related information mostly through the Internet, friends, family, physicians, and health staff, respectively (Table 2). The mean health literacy score of the participants was $125.99 \pm 16.01$. The health literacy status was good, medium, and poor among $15.8 \%, 70.6 \%$, and $13.6 \%$ of the participants, respectively. The mean health literacy score in the dimensions of reading and evaluation was lower than other dimensions among the participants (Table 3). Pearson's correlation coefficient test and its nonparametric counterpart, namely Spearman's correlation coefficient, indicated significantly positive correlation between the health literacy scores and age $(\mathrm{r}=0.19, \mathrm{p}=0.0001)$, access $(\mathrm{r}=0.57, \mathrm{p}=0.0001)$, reading $(\mathrm{r}=0.617, \mathrm{p}=0.0001)$, understanding $(\mathrm{r}=0.78, \mathrm{p}=0.0001)$, evaluation $(\mathrm{r}=0.70, \mathrm{p}=0.0001)$, application and decision-making ( $\mathrm{r}=0.84$, $\mathrm{p}=0.0001$ ). Also, performing a Kruskal-Wallis test revealed a significant relationship between age and health literacy so that the participants with the age of above 46 years old had a better health literacy status $(p=0.0001)$. Moreover, a significant relationship was found between age and dimensions of reading $(p=0.019)$, understanding $(p=0.004)$, and decision-making and application $(p=0.0001)$ so that the participants with the age of above 46 years old had a better health literacy status. Also, based on ANOVA and its non-parametric counterpart, namely KruskalWallis test, it was shown that there was a statistically significant relationship between health literacy and dimensions of access $(\mathrm{p}=0.0001)$, reading $(\mathrm{p}=0.0001)$, understanding $(\mathrm{p}=0.0001)$, evaluation $(\mathrm{p}=0.0001)$, and decision-making $(\mathrm{p}=0.0001)$ so that the higher the score of heath literacy dimensions, the better the score of health literacy would be. Chi-square test revealed significant relationships between the dimension of access and education level $(p=0.0001)$, occupational rank $(p=0.0001)$, work experience $(p=0.005)$, between dimension of reading and education level $(p=0.0001)$, occupational rank $(p=0.0001)$, work experience $(p=0.005)$, between dimension of understanding and sex $(p=0.019)$, education level $(p=0.0001)$, occupational rank $(p=0.0001)$, work place $(p=0.031)$, between dimension of evaluation and sex $(p=0.02)$, education level $(p=0.0001)$, occupational rank $(p=0.0001)$, work place $(p=0.0001)$, and between dimensions of decision-making and education level $(\mathrm{p}=0.0001)$, occupational rank $(\mathrm{p}=0.0001)$, work place $(\mathrm{p}=0.0001)$, and work experience $(\mathrm{p}=0.01)$. 
Table1. Health literacy level based on population variable

\begin{tabular}{|c|c|c|c|c|c|c|c|}
\hline \multicolumn{2}{|c|}{ Demographic characteristics } & \multirow{3}{*}{\begin{tabular}{|l|} 
n \\
149 \\
211
\end{tabular}} & \multirow{2}{*}{\begin{tabular}{|l|}
$\%$ \\
41.4 \\
\end{tabular}} & \multirow{2}{*}{$\begin{array}{l}\text { Poor } \\
\text { health } \\
\text { literacy; n (\%) } \\
21(45.7) \\
\end{array}$} & \multirow{2}{*}{$\begin{array}{l}\text { Medium } \\
\text { health literacy; } \\
\text { n (\%) }\end{array}$} & \multirow{2}{*}{$\begin{array}{l}\text { Good health } \\
\text { literacy; n (\%) }\end{array}$} & \multirow{2}{*}{\begin{tabular}{|l|}
$\begin{array}{l}\text { p-value (Chi- } \\
\text { square) }\end{array}$ \\
0.48
\end{tabular}} \\
\hline \multirow[t]{2}{*}{ Sex } & Female & & & & & & \\
\hline & Male & & 58.6 & $25(54.3)$ & $150(57.9)$ & $36(65.5)$ & \\
\hline \multirow[t]{4}{*}{ Education level } & $\begin{array}{l}\text { High school } \\
\text { diploma }\end{array}$ & 71 & 19.7 & $95(32.6)$ & $52(20.1)$ & $4(7.3)$ & \multirow[t]{4}{*}{$0.0001 *$} \\
\hline & Associate degree & 39 & 10.8 & $12(26.1)$ & $26(10.0)$ & $1(1.8)$ & \\
\hline & $\mathrm{BSc}$ & 128 & 35.6 & $10(21.7)$ & $97(37.5)$ & $21(38.2)$ & \\
\hline & M.Sc. and higher & 122 & 33.9 & $9(19.6)$ & $84(32.4)$ & $29(59.7)$ & \\
\hline \multirow{5}{*}{$\begin{array}{l}\text { Occupational } \\
\text { ranking }\end{array}$} & Head & 1 & 0.3 & $0(0)$ & $0(0)$ & $1(1.8)$ & \multirow[t]{5}{*}{$0.0001 *$} \\
\hline & Manager & 28 & 7.8 & $0(0)$ & $16(6.2)$ & $12(21.8)$ & \\
\hline & Senior expert & 19 & 5.3 & $1(2.2)$ & $10(3.9)$ & $8(14.5)$ & \\
\hline & Expert & 202 & 56.1 & $17(37)$ & $156(60.2)$ & $29(52.7)$ & \\
\hline & Normal & 110 & 30.6 & $28(60.9)$ & $77(29.7)$ & $5(9.1)$ & \\
\hline \multirow[t]{4}{*}{ Work place } & Municipality & 48 & 13.3 & $2(4.3)$ & $37(14.3)$ & $9(416)$ & \multirow[t]{4}{*}{$0.0001^{*}$} \\
\hline & Research center & 92 & 25.6 & $13(28.3)$ & $72(27.8)$ & $7(12.7)$ & \\
\hline & City bank & 60 & 16.7 & $5(10.9)$ & $33(12.7)$ & $22(40)$ & \\
\hline & $\begin{array}{l}\text { Municipality of } \\
\text { Region } 1\end{array}$ & 160 & 44.4 & $26(56.5)$ & $117(45.2)$ & $17(30.9)$ & \\
\hline \multirow{2}{*}{$\begin{array}{l}\text { Work experience } \\
\text { (year) }\end{array}$} & $<10$ & 245 & 68.1 & $42(91.3)$ & $168(64.9)$ & 35 (63.6) & \multirow[t]{2}{*}{$0.0001 *$} \\
\hline & $\geq 10$ & 115 & 31.9 & $4(8.7)$ & $91(32.1)$ & $20(36.4)$ & \\
\hline
\end{tabular}

Table 2. Levels of health literacy based on information source

\begin{tabular}{|c|c|c|c|c|c|c|c|}
\hline \multirow{2}{*}{$\begin{array}{l}\text { Health } \\
\text { Literacy } \\
\text { Status }\end{array}$} & \multicolumn{7}{|c|}{ Information source; $\mathrm{n}(\%)$} \\
\hline & $\begin{array}{l}\text { Physicians and } \\
\text { health staff }\end{array}$ & Internet & IVR & $\begin{array}{l}\text { Radio and } \\
\text { television }\end{array}$ & $\begin{array}{l}\text { Newspapers, } \\
\text { journals, magazines }\end{array}$ & $\begin{array}{l}\text { Friends, } \\
\text { family }\end{array}$ & \begin{tabular}{|l} 
Booklets and \\
brochures
\end{tabular} \\
\hline Good & $35(63.6)$ & $37(67.3)$ & $0(0)$ & $22(40)$ & $14(25.5)$ & $11(20)$ & $13(23.6)$ \\
\hline Medium & $84(32.4)$ & 175 67.6) & $5(1.9)$ & $121(46.7)$ & $58(22.4)$ & $99(38.2)$ & $42(16.2)$ \\
\hline Poor & $4(8.7)$ & $21(45.7)$ & $1(2.2)$ & $28(60.9)$ & $6(13)$ & $30(65.2)$ & $43(93.5)$ \\
\hline Total & $123(34.2)$ & $233(64.7)$ & $6(1.7)$ & $171(47.5)$ & $78(21.7)$ & $140(38.9)$ & $302(83.9)$ \\
\hline $\begin{array}{l}\text { p-value (Chi- } \\
\text { square) }\end{array}$ & 0.0001 & 0.015 & 0.77 & 0.1 & 0.27 & 0.0001 & 0.066 \\
\hline
\end{tabular}

Table 3. Mean health literacy score based on the health literacy dimensions

\begin{tabular}{|l|l|l|l|l|}
\hline \multirow{2}{*}{ Dimensions } & \multicolumn{4}{l}{ Health literacy score } \\
\cline { 2 - 5 } & Mean \pm SD & Poor; $\mathrm{n}(\%)$ & Medium; n (\%) & Good; n (\%) \\
\hline Access & $21.37 \pm 2.91$ & $59(16.4)$ & $239(66.4)$ & $62(17.2)$ \\
\hline Reading & $15.36 \pm 2.89$ & $48(13.3)$ & $258(71.7)$ & $54(15)$ \\
\hline Understanding & $28.33 \pm 3.8$ & $53(14.7)$ & $245(68.1)$ & $62(17.2)$ \\
\hline Health literacy evaluation & $15.01 \pm 2.8$ & $72(20)$ & $216(60)$ & $72(20)$ \\
\hline Decision-making & $44.20 \pm 7.79$ & $52(14.4)$ & $242(67.2)$ & $66(18.3)$ \\
\hline Total health literacy & $125.99 \pm 16.01$ & $49(13.6)$ & $254(70.6)$ & $57(15.8)$ \\
\hline
\end{tabular}

\section{Discussion}

The overall health literacy status was at a medium level among most of the participants. The mean health literacy score in the dimensions of reading and evaluation was lower than other dimensions among the participants and the internet was the significant source for health information. According to the study by Pirdehghan et al., $75.2 \%$ of the participants had a poor health literacy level using S-TOFLA (6). In a work by Von Wagner et al., only $11.4 \%$ of the participants had poor health literacy (16). In the study conducted by Sharifirad et al., the health literacy level of the elderly was very poor (1). Findings of this study emphasized the necessity of designing the promotional interventions to improve the health literacy of the staff. 
In the present study, there was a statistically significant relationship between health literacy and age, education level, and information source, so that the participants with the age of above 46 years old and education level of MSc and above, had higher health literacy levels. A similar study by Zareban et al. also showed the relationship between health literacy level and age, education level, and information source (15). Based on the findings of this study, planning the educational interventions is a priority for improving the health literacy status of the employees with lower educational level and lower age. Findings of this study indicated a statistically significant relationship between the health literacy dimensions of access, understanding, and evaluation and sex so that the scores of these dimensions were higher among men. In the study by Javadzade et al., poor health literacy was reported among women. However, in the study by Montazeri et al., the health literacy status was $67.6 \%$ and $69.02 \%$ for men and women, respectively (7). Such a difference could be due to the difference of the studied samples and research time. Based on this finding, it is necessary to perform educational interventions for female employees in order to improve the access, understanding, and evaluation dimensions of health literacy. In the present study, there was a statistically significant relationship between the health literacy dimensions and health literacy level so that the employees with higher scores in each of the health literacy dimensions had better total health literacy scores. In terms of the correlation between the health literacy components, a similar study was conducted by Peyman et al. on investigating the health literacy status of the nurse assistants based on TOFLA questionnaire (17). Accordingly, it is necessary to plan a program for promoting the status of each of the health literacy dimensions in order to improve the overall health literacy among them. Results of this study showed a statistically significant relationship between the dimensions of access, understanding, reading, evaluation, and decision-making with occupational rank and work experience so that the scores of the health literacy dimensions were higher among the participants with occupational ranking of expert and work experience of above 10 years. The reason was that most of the participants had an educational level of BSc and work experience of less than 10 years. With respect to this finding, it is necessary to focus on the staff with other occupational rankings and work experience of above 10 years in planning for promoting the health literacy status of these employees. In this study the mean scores of access, understanding and decision-making dimensions were more than other dimensions. This finding is consistent with Pratt, Searles and Edwards's studies $(18,19)$. Findings of the study showed the mean score of reading and evaluation dimensions were less than other dimensions. Similar research had been reported by Mirand (20). Therefore, using visual aids for increasing reading skills and increasing communications and evaluation skills could lead to health literacy promotion. The study on the office employees in Shemiranat County, self-reporting, and quantitative method were the limitations of the present study. It is proposed to conduct similar studies on the employees in other offices, other regions, and other residents of this county and to use the interview method.

\section{Conclusions}

The health literacy status among the studied employees was at medium level, which is not sufficient. It is recommended to perform promotional interventions in order to improve health literacy status and its dimensions among these employees through planning educational programs to hold workshops, and preparing and distributing booklets and health training software in offices, with the cooperation of the experts of Department of Health Education and Health Promotion at universities of medical sciences.

\section{Acknowledgments:}

Authors would like to acknowledge the authorities of Area 5, Municipality District 1, Research Centre of Municipality, senior experts of the municipality, Shahr Bank, questioners and all the staff participating in this project. Also, authors appreciate the efforts of Mr. Mirzapur, Mr. Jahangiri and Mr. Nazemi for facilitating data collection.

\section{Conflict of Interest:}

There is no conflict of interest to be declared.

\section{Authors' contributions:}

MS designed the study. HJ performed the study. MS and HJ drafted the manuscript. MS and HJ performed statistical analysis and interpretation of data. Both authors read and approved the final manuscript.

\section{References:}

1) Raeisi M, Mostafavi F, Hasanzadeh A, Sharifirad GR. The relationship between health literacy and general health status and health behaviors in elderly. Health System Research. 2011; (4): 469-80. 
2) Aydin GO, Kaya N, Turan N. The Role of Health Literacy in Access to Online Health Information. Procedia - Social and Behavioral Sciences. 2015; 195: 1683 -7. doi: 10.1016/j.sbspro.2015.06.252.

3) Fadda M, Kanj M, Kabakian-Khasholian T, Johannes Schulz P. Validation of three Arabic health literacy assessment tools in Lebanon. Health Promot International. 2016. doi: 10.1093/heapro/daw079.

4) Rutherford EJ, Kelly J, Lehane EA, Livingstone V, Cotter B, Butt A, et al. Health literacy and the perception of risk in a breast cancer family history clinic. Surgeon. 2016. doi: 10.1016/j.surge.2016.06.003. PMID: 27908542.

5) Palumbo R, Annarumma C, Adinolfi P, Musella M, Piscopo G. The Italian Health Literacy Project: Insights from the assessment of health literacy skills in Italy. Health Policy. 2016; 120(9): 1087-94. doi: 10.1016/j.healthpol.2016.08.007. PMID: 27593949.

6) Pirdehghan A, Colleges. Evaluation of health education staff in relation to risk factors for chronic diseases in 2015. Scientific Journal of Hamedan University of Medical Sciences. 2015; 22(3): 248-53.

7) Tavousi M, Haeri Mehrizi AA, Rafiefar Sh, Soleimanian A, Sarbandi F, Ardestani M, et al. Health Literacy in Iran: Finding from National Study. Journal of the Iranian Institute for Health Sciences Research. Payesh. 2015; 15(1): 95-102.

8) Van den Broucke S. Health literacy: a critical concept for public health. Arch Public Health. 2014; 72(10). doi: 10.1186/2049-3258-72-10. PMID: 24685171, PMCID: PMC3994208.

9) Elder C, Barber M, Staples M, Osborne R, Clerehan R, Buchbinder R. Assessing Health Literacy: a new domain for collaboration between language testers and health professionals. Language Assessment Quarterly. 2012; 9(3): 205-24. doi: 10.1080/15434303.2011.627751.

10) Kuczmarski MF, Adams EL, Cotugna N, Pohlig RT, Beydoun MA, Zonderman AB, et al. Health Literacy and Education Predict Nutrient Quality of Diet of Socioeconomically Diverse, Urban Adults. J Epid Prev Med. 2016; 2(1). doi: 10.19104/jepm.2016.115.

11) De Oliveira MO, Nitrini R, Brucki SM. The S-TOFHLA as a measure of functional literacy in patients with mild Alzheimer's disease or mild cognitive impairment. Arch Clin Neuropsychol. 2014; 29(3): 269-77. doi: 10.1093/arclin/act120. PMID: 24503948.

12) Linnebur LA, Linnebur SA. Self-Administered Assessment of Health Literacy in Adolescents Using the Newest Vital Sign. Health promotion practice. 2016. doi: 10.1177/1524839916677729.

13) Cordasco KM, Homeier DC, Franco I, Wang PC, Sarkisian CA. Health literacy screening of geriatric monolingual Spanish-speaking patients using single-item literacy screening questions and education. Health Educ. 2012; 71(5): 597-605. doi: 10.1177/0017896911411764. PMID: 23788818, PMCID: PMC3685504.

14) Montazeri A, Tavousi M. Health literacy for Iranian adults (HELIA) development and psychometric properties. Payesh. 2014; 13(5): 589-99.

15) Zareban I, Izadirad H. Evaluation of health literacy, health status and health services utilization in women in Baluchestan region of Iran. Journal of health literacy. 2015; 1(2): 71-82.

16) Von Wagner C, Knight K, Steptoe A, Wardle J. Functional health literacy and health-promoting behavior in a national sample of British adults. Journal of epidemiology and community health. 2007; 61(12): 108690, doi: 10.1136/jech.2006.053967.

17) Peyman N, Samiee-roudi Kh. Investigating the status of health literacy among health providers of rural area. Journal of Health literacy. 2016; 1(1): 46-52.

18) Pratt M, Searles GE. Using Visual Aids to Enhance Physician-Patient Discussions and Increase Health Literacy. J Cutan Med Surg. 2017: 1203475417715208. doi: 10.1177/1203475417715208. PMID: 28614954.

19) Edwards M, Wood F, Davies M, Edwards A. The development of health literacy in patients with a longterm health condition: the health literacy pathway model. BMC public health. 2012; 12: 130. doi: 10.1186/1471-2458-12-130. PMID: 22332990, PMCID: PMC3305618.

20) Miranda C. Health Literacy and Health Decision Making Attitudes in People with Human Immunodeficiency Virus. Minneapolis: Walden University; 2015: 132. 